\title{
Local Sensitivity Analysis of COVID-19 Epidemic with Quarantine and Isolation using Normalized Index
}

\author{
Muhammad Abdurrahman Rois ${ }^{1}$, Trisilowati $^{2}$, Ummu Habibah $^{3}$ \\ ${ }^{1,2,3}$ Department of Mathematics, Faculty of Mathematics and Natural Sciences, Brawijaya University \\ E-mail: roizmuhammad.math@gmail.com ${ }^{1}$, trisilowati@ub.ac.id ${ }^{2}$, ummu_habibah@ub.ac.id ${ }^{3}$
}

\section{A R T I C L E I N F O}

History of the article:

Received December 19, 2020

Revised January 12, 2021

Accepted February 25, 2021

\section{Keywords:}

COVID-19 model,

Runge-Kutta fourth-order,

Next-generation matrix,

Sensitivity analysis

\section{Correspondece:}

Telephone: +6281914430369

E-mail:

roizmuhammad.math@gmail.com

\section{ABSTRACT}

This study discusses the sensitivity analysis of parameters, namely the COVID19 model, by dividing the population into seven subpopulations: susceptible, exposed, symptomatic infection, asymptomatic infection, quarantine, isolation, and recovered. The solution to the ordinary differential equation for the COVID19 model using the fourth-order Runge-Kutta numerical method explains that COVID-19 is endemic, as evidenced by the basic reproduction number $\left(R_{0}\right)$ of 7.5. It means 1 individual can infect 7 to 8 individuals. Then $R_{0}$ is calculated using the next-generation matrix method. Based on the value of $R_{0}$, a parameter sensitivity analysis is implemented to specify the most influential parameters in the spread of the COVID-19 outbreak. This can provide input on the selection of appropriate control measures to solve the epidemic from COVID-19. The results of the sensitivity analysis are the parameters that have the most influence on the model, namely $\Lambda, q_{1}, q_{2}, \sigma, \beta_{2}, \gamma_{3}, \beta_{3}, \beta_{1} d, \gamma_{1}, \omega, \theta, \mu$.

\section{INTRODUCTION}

COVID-19 first appeared and was identified in Wuhan, China, around December 2019 (Chen et al., 2020), then spread to various countries rapidly through people who had a history of travel to Wuhan (Tang et al., 2020; WHO, 2020; Yousefpour, Jahanshahi, \& Bekiros, 2020). On October 2, 2020, COVID-19 caused a total of $34,819,505$ cases in the world to be positively infected. The latest information was on October 2, 2020, more than 34 million infected cases in the world, with 1,032,741 deaths have been reported. In Indonesia's first case on March 2, 2020, there were 2 people who were infected, namely a mother and child who were suspected of contracting from a Japanese citizen (Sumartiningtyas, 2020). While on October 2, 2020, data from the web Worldometer that Indonesia ranks 23 out of 215 countries reported as infected with 295,499 confirmed cases, 10,972 deaths, and 221,340 recoveries. The number of COVID-19 cases in Indonesia continues to increase every day. The government has made various efforts to control COVID-19, such as social distancing, tracing, and working from home. Apart from some areas, the government has also imposed very stick territorial restrictions.

The mathematical model that can describe the spread of disease is SIR (Susceptible-InfectedRecovered) model. SIR model was first introduced by Kermack and McKendrick (1927), then became a source of reference and played a role in the development of mathematics about the transmission of infectious diseases (Müller \& Kuttler, 2015; Murray, 2002). Modeling of the COVID-19 case has been widely carried out with various models starting from research conducted by Soewono (2020) using SEIR model, SEIAR model (Belgaid, Helal, \& Venturino, 2020), SEIHR model (Zeb, Alzahrani, Erturk, \& 
Zaman, 2020), and SEIAQHR model (Jia et al., 2020). This study uses the SEIAQHR model based on conditions in Indonesia and a combination of research from Belgaid et al. (2020), Jia et al. (2020), and Zeb et al. (2020). The steps taken in this research are first, the construction of the COVID-19 model with quarantine and isolation is carried out. Second, $R_{0}$ value is obtained which is calculated by the nextgeneration matrix method. Furthermore, a sensitivity analysis is implemented to show the most significant parameters in the spread of COVID-19.

\section{RESEARCH METHODS}

\section{Tools and Materials}

In this study, the tools and materials used are as follows: (i) MATLAB 2017. (ii) Computer with processor specifications intel i5-8250U, RAM 8GB, and Windows 10 64-bit operation.

\section{Research Flow}

In this study, the following steps were carried out:

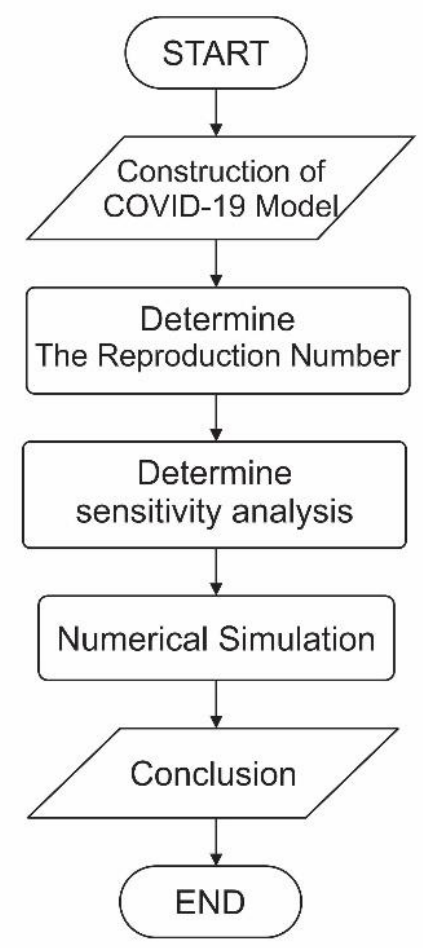

Figure 1. Flowchart of the COVID-19 model sensitivity analysis research

The explanation of the research steps are as follows:

a. Construction of COVID-19 model

This model uses the SEIAQHR model based on conditions in Indonesia and a combination of research from Belgaid et al., Jia et al., and Zeb et al. in 2020 about the COVID-19 model.

b. Basic reproduction numbers $\left(R_{0}\right)$

$R_{0}$ is the average number of newly infected individuals caused by one infected individual in a susceptible population. $R_{0}$ is used to determine the spread of disease and predict a population can endanger or not. The conditions that arise are among the following possibilities (Heffernan, Smith, \& Wahl, 2005): (i) If $R_{0}<1$, it means that an infected individual can transmit the disease on average less than one newly infected individual, so it can be predicted that the infection will disappear and there will be no spread of disease, or it is called disease-free. (ii) If $R_{0}>1$, it means 
that an infected individual can transmit the disease on average more than one newly infected individual, causing it to easily spread the disease.

Furthermore, the next-generation matrix (NGM) is one method to determining $R_{0}$. In the NGM method, the compartment model used is the infected compartment (Brauer \& CastilloChavez, 2012). Furthermore, the infected compartment model can be written as:

$$
\frac{d x}{d t}=f-v .
$$

So, obtained

$$
F=\frac{\partial f\left(E_{0}\right)}{\partial x}, V=\frac{\partial v\left(E_{0}\right)}{\partial x} .
$$

NGM is defined as $M=F V^{-1}$ and $R_{0}$ can be obtained from $R_{0}=\rho(M)$, where $\rho(M)$ is the spectral radius of the matrix $M$, which is the largest modulus of the eigenvalues of the matrix $M$.

c. Parameter sensitivity analysis

Parameter sensitivity analysis is used to identify the effect of each parameter on disease spread based on $R_{0}$, this can provide input in the selection of appropriate control measures to prevent an outbreak from COVID-19. The sensitivity analysis is divided into two based on Ingalls (2012) is: (i) Global sensitivity analysis, which discusses the wide variation in a parameter value which is often implemented using the Monte-Carlo method, and (ii) Local sensitivity analysis, namely discussing local variations around, using the one-at-a-time (OAT) technique, which is the most basic method with partial differentiation, in which various value parameters are taken one by one.

In the local sensitivity analysis using the normalized sensitivity index. The normalized sensitivity index is defined as follows (Chitnis, Hyman, \& Cushing, 2008):

$$
C_{V}^{p}=\frac{\partial V}{\partial p} \frac{p}{V}
$$

Where $V$ is the variable to be analyzed, and $p$ is the parameter.

d. The fourth-order Runge-Kutta

The fourth-order Runge-Kutta is a numerical method commonly used to solve ordinary differential equations (Lenhart and Workman, 2007). In the initial value problem, if $\frac{d y}{d t}=f(t, y(t))$ and $y(t)$ is known. The value of $y(t+h)$ can be approximated by

$$
y(t+h) \approx y(t)+\frac{h}{6}\left(n_{1}+2 n_{2}+2 n_{3}+n_{4}\right),
$$

With:

$$
\begin{aligned}
& n_{1}=f(t, y(t)), \\
& n_{2}=f\left(t+\frac{1}{2} h, y(t)+\frac{1}{2} h n_{1}\right), \\
& n_{3}=f\left(t+\frac{1}{2} h, y(t)+\frac{1}{2} h n_{2}\right), \\
& n_{4}=f\left(t+h, y(t)+h n_{3}\right),
\end{aligned}
$$

Where: 
$n_{1}$ is use $x$ for the slope at the beginning of the interval,

$n_{2}$ is use $x$ and $m_{1}$ for the slope at the midpoint of the interval,

$n_{3}$ is again the slope at the midpoint but now using $x$ and $m_{2}$,

$n_{4}$ is use $x$ and $m_{3}$ for the slope at the end of the interval.

\section{RESULTS AND DISCUSSION}

The construction of the COVID-19 model with quarantine and isolation is given as follows:

$$
\begin{aligned}
& \frac{d S}{d t}=\Lambda-S\left(\beta_{1} E+\beta_{2} I+\beta_{3} A+\mu+q_{1}\right), \\
& \frac{d E}{d t}=S\left(\beta_{1} E+\beta_{2} I+\beta_{3} A\right)-E\left(\mu+\sigma+q_{2}\right), \\
& \frac{d I}{d t}=\sigma \omega E+\theta A-I\left(\gamma_{1}+\mu+d\right), \\
& \frac{d A}{d t}=(1-\omega) \sigma E-A\left(\gamma_{3}+\theta+\mu\right), \\
& \frac{d Q}{d t}=q_{1} S+q_{2} E-Q\left(\mu+\gamma_{2}+r_{2}\right), \\
& \frac{d H}{d t}=\gamma_{1} I+\gamma_{2} Q+\gamma_{3} A-H\left(\mu+r_{1}\right), \\
& \frac{d R}{d t}=r_{1} H+r_{2} Q-\mu R .
\end{aligned}
$$

Description

$\Lambda$ : Human recruitment rate,

$\beta_{1}$ : Contact rate of susceptible subpopulations with exposed,

$\beta_{2}$ : Subpopulation's contact rate is susceptible to symptomatic,

$\beta_{3}$ : Subpopulation's contact rate is susceptible to asymptomatic,

$\mu:$ Rate of natural death,

$d:$ Rate of death due to COVID-19,

$q_{1}$ : Rate of susceptible individuals quarantined,

$q_{2}$ : Rate of exposed individuals quarantined,

$\alpha$ : Rate of return of individuals to susceptible subpopulations after quarantine,

$\gamma_{1}$ : Isolation rate from symptomatic subpopulations,

$\gamma_{2}$ : Isolation rate from quarantine subpopulation,

$\gamma_{3}$ : Isolation rate from asymptomatic subpopulation,

$\theta:$ Rate of asymptomatic individuals becomes symptomatic,

$r_{1}:$ Recovery rate after isolation,

$r_{2}:$ Recovery rate after quarantine,

$\sigma$ : Rate of progression from exposed to symptomatic,

$\omega$ : Proportion of becoming infected is symptomatic.

Based on the system of equation (6), $R_{0}$ is obtained using the next-generation matrix as follows: 


$$
R_{0}=\rho(M)=\frac{\Lambda}{h_{1} h_{2}}\left(\beta_{1}+\frac{\beta_{2} \sigma\left(h_{4} \omega-\theta \omega+\theta\right)}{h_{3} h_{4}}+\frac{\beta_{3} \sigma(1-\omega)}{h_{4}}\right)
$$

with

$h_{1}=\mu+q_{1}, h_{2}=\mu+\sigma+q_{2}, h_{3}=\gamma_{1}+\mu+d$, dan $h_{4}=\gamma_{3}+\theta+\mu$.

\section{Preliminary data}

The parameters used in research in the Indonesia region are as follows:

Table 1. Parameters used in the COVID-19 model

\begin{tabular}{|c|c|c|c|}
\hline Parameter & $\begin{array}{l}\text { Parameter } \\
\text { Value }\end{array}$ & Description & Source \\
\hline$\Lambda$ & 1.685 & Human recruitment rate $\left(\frac{\text { individual }}{\text { day } \times 1,00}\right)$ & Assumed \\
\hline$\mu$ & $3.9139 \times 10^{-5}$ & Natural date rate $\left(\frac{1}{\text { day }}\right)$ & $\begin{array}{l}\text { (Aldila, Ndii, \& } \\
\text { Samiadji, 2020) }\end{array}$ \\
\hline$\sigma$ & 0.196 & $\begin{array}{l}\text { Rate of progression from exposed to } \\
\text { symptomatic }\end{array}$ & Assumed \\
\hline$\theta$ & 0.01 & $\begin{array}{l}\text { Rate of asymptomatic individuals becomes } \\
\text { symptomatic }\left(\frac{1}{\text { day }}\right)\end{array}$ & $\begin{array}{l}\text { (Aldila, Ndii, \& } \\
\text { Samiadji, 2020) }\end{array}$ \\
\hline$\omega$ & 0.4 & $\begin{array}{c}\text { Proportion of becoming infected is } \\
\text { symptomatic }\end{array}$ & $\begin{array}{l}\text { (Aldila, Ndii, \& } \\
\text { Samiadji, 2020) }\end{array}$ \\
\hline$d$ & 0.087 & Death rate due to COVID-19 & $\begin{array}{l}\text { (Sasmita, Ikhwan, } \\
\text { Suyanto, \& } \\
\text { Chongsuvivatwong, } \\
\text { 2020) }\end{array}$ \\
\hline$q_{1}$ & 0.09 & $\begin{array}{l}\text { Rate of susceptible individuals quarantined } \\
\qquad\left(\frac{1}{\text { day }}\right)\end{array}$ & Assumed \\
\hline$q_{2}$ & 0.1 & $\begin{array}{l}\text { Rate of exposed individuals quarantined } \\
\qquad\left(\frac{1}{\text { day }}\right)\end{array}$ & Assumed \\
\hline$\beta_{1}$ & 0.01 & $\begin{array}{l}\text { Contact rate of susceptible subpopulations } \\
\quad \text { with exposed }\left(\frac{1}{\text { individual } \times \text { day }}\right)\end{array}$ & Assumed \\
\hline$\beta_{2}$ & 0.4 & $\begin{array}{l}\text { Subpopulation's contact rate is susceptible to } \\
\text { symptomatic }\left(\frac{1}{\text { individual } \times \text { day }}\right)\end{array}$ & Assumed \\
\hline$\beta_{3}$ & 0.4 & $\begin{array}{l}\text { Subpopulation's contact rate is susceptible to } \\
\quad \text { asymptomatic }\left(\frac{1}{\text { individual } \times \text { day }}\right)\end{array}$ & Assumed \\
\hline \multicolumn{4}{|c|}{ Table 2. Next parameters used in the COVID-19 model } \\
\hline Parameter & $\begin{array}{l}\text { Parameter } \\
\text { Value }\end{array}$ & Description & Source \\
\hline$\gamma_{1}$ & 0.083 & $\begin{array}{l}\text { Isolation rate from symptomatic } \\
\text { subpopulations }\left(\frac{1}{\text { day }}\right)\end{array}$ & $\begin{array}{l}\text { (Aldila, Ndii, \& } \\
\text { Samiadji, 2020) }\end{array}$ \\
\hline$\gamma_{2}$ & 0.01 & $\begin{array}{l}\text { Isolation rate from quarantine subpopulation } \\
\qquad\left(\frac{1}{\text { day }}\right)\end{array}$ & $\begin{array}{l}\text { (Aldila, Ndii, \& } \\
\text { Samiadji, 2020) }\end{array}$ \\
\hline$\gamma_{3}$ & 0.2435 & $\begin{array}{l}\text { Isolation rate from the asymptomatic } \\
\text { subpopulation }\left(\frac{1}{\text { day }}\right)\end{array}$ & $\begin{array}{l}\text { (Aldila, Ndii, \& } \\
\text { Samiadji, 2020) }\end{array}$ \\
\hline$r_{1}$ & 0.1 & Recovery rate after isolation $\left(\frac{1}{d a y}\right)$ & $\begin{array}{l}\text { (Aldila, Ndii, \& } \\
\text { Samiadji, 2020) }\end{array}$ \\
\hline$r_{2}$ & 0.125 & Recovery rate after quarantine $\left(\frac{1}{\text { day }}\right)$ & $\begin{array}{l}\text { (Aldila, Ndii, \& } \\
\text { Samiadji, 2020) }\end{array}$ \\
\hline
\end{tabular}

\section{Model completion}

Using Runge Kutta Formulas in equation (4) to find the next value from equations (6) as follows: 


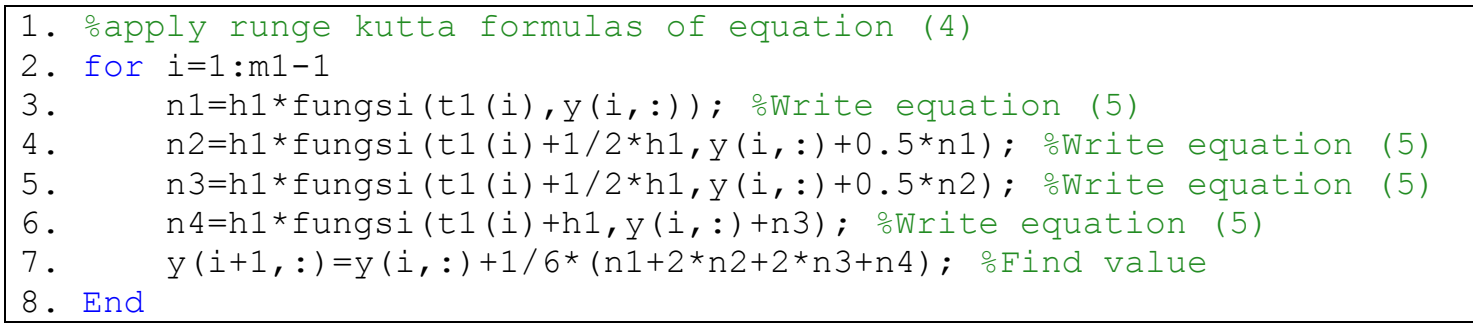

and the function program of a system (6) is presented as follows:

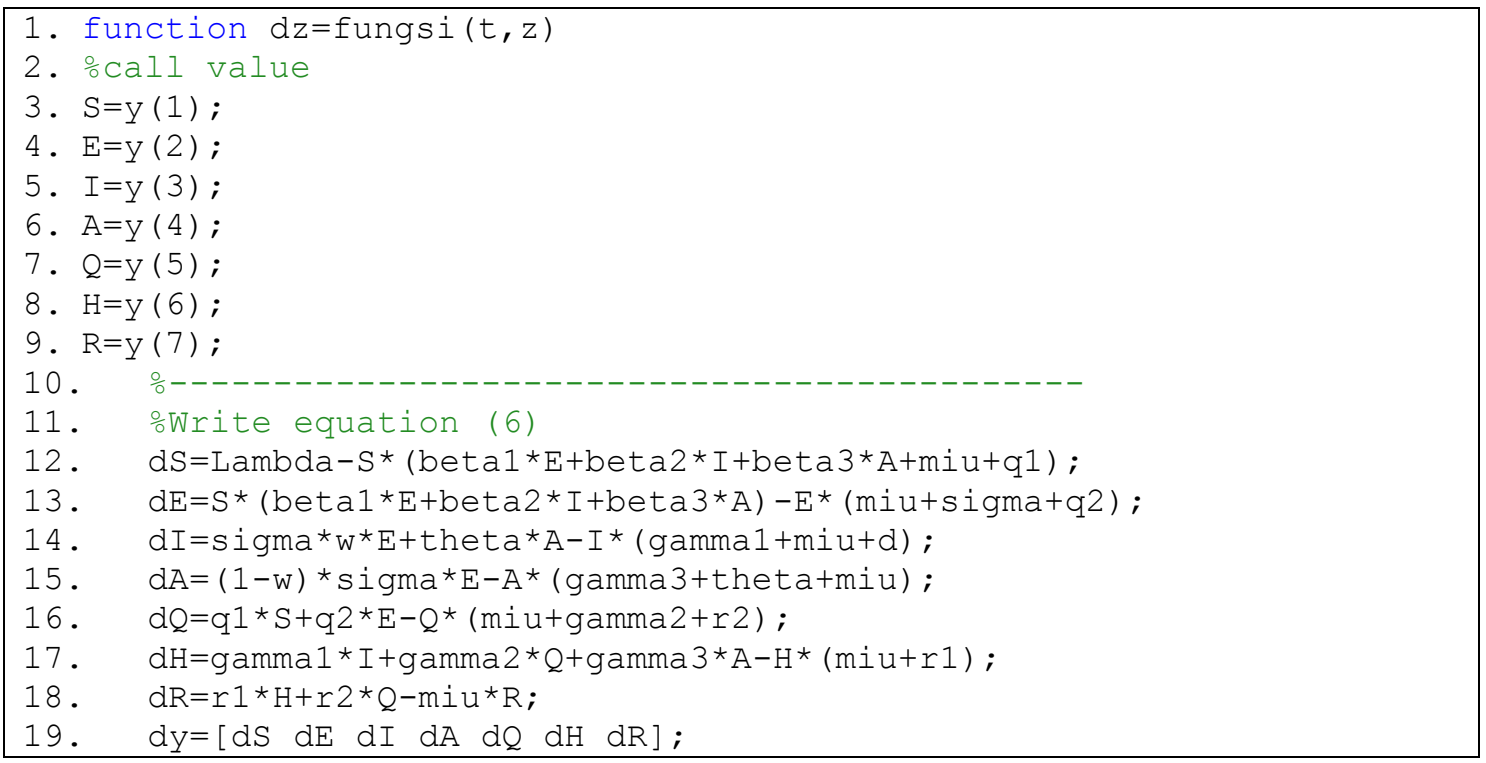

Furthermore, Figure 2 (a) - (g) is obtained by the following command:

\begin{tabular}{|c|}
\hline 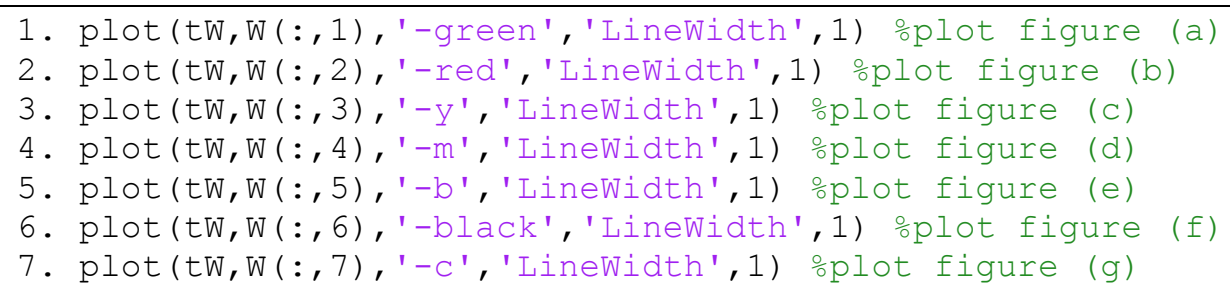 \\
\hline
\end{tabular}

Based on parameters in Table 1 and Table 2, it can be seen that the susceptible $(S)$ is significantly reduced in Figure 2 (a). Then Figures 2 (b), (c), (d) show exposed (E), symptomatic (I), and asymptomatic (A) up significantly and down significantly, but in a certain period until the end of the time, there are still individuals exposed, symptomatic and asymptomatic. Therefore, endemic diseases still epidemic during this period. Figures 2 (e), (f) show the quarantine $(Q)$ and isolation $(H)$ subpopulations showing significant increases and decreases due to overcoming the spike in the exposed, symptomatic and asymptomatic subpopulations. Furthermore, the subpopulation of quarantine and isolation after a certain time until the end of time remains. The recovered subpopulation $(R)$ in Figure $2(\mathrm{~g})$ shows that the recovery overtime is increasing. 


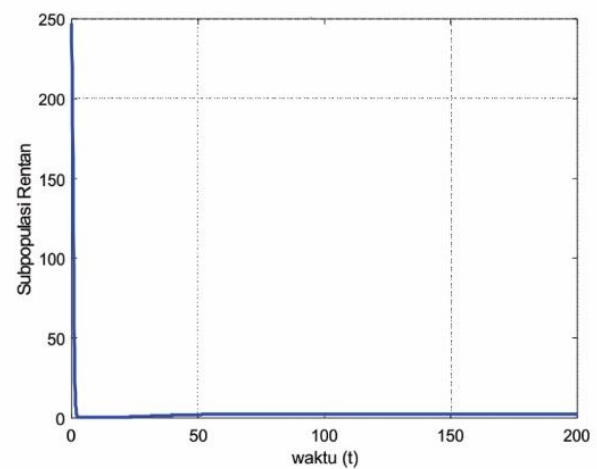

(a)
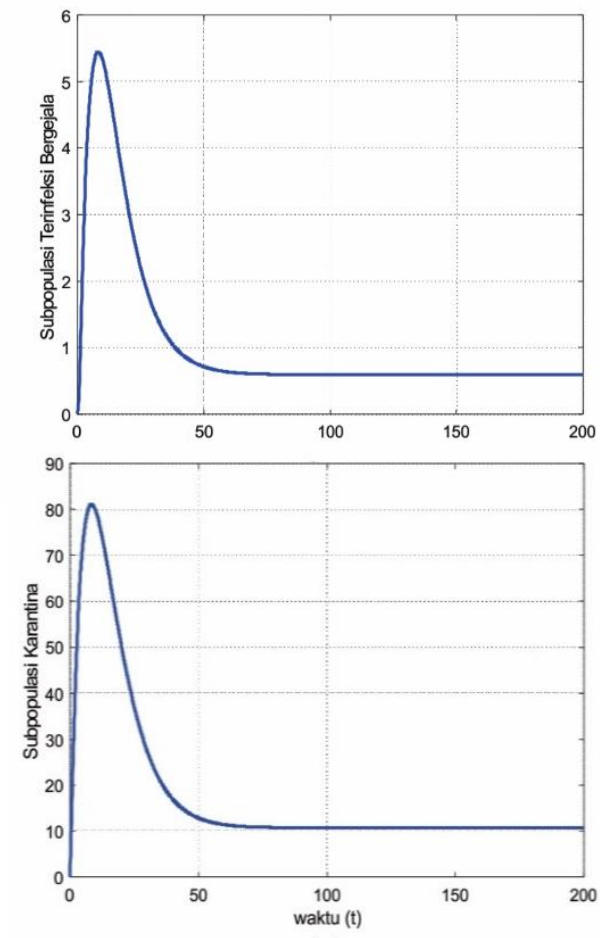

(e)

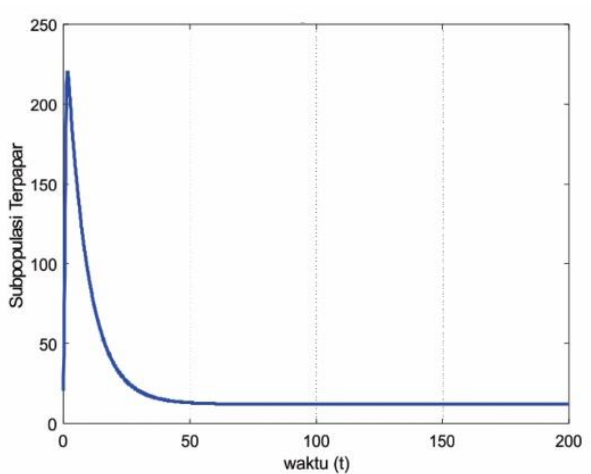

(b)
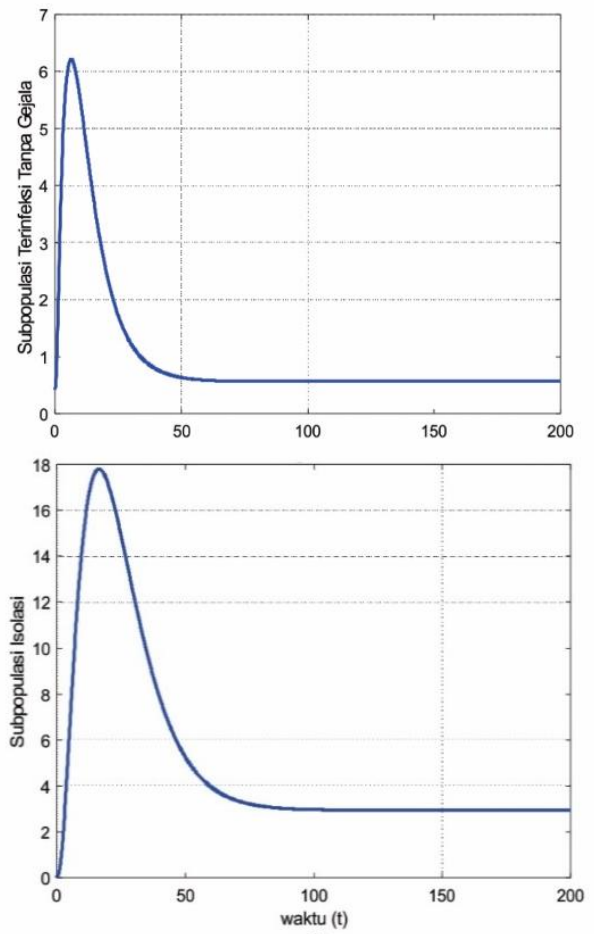

(f)

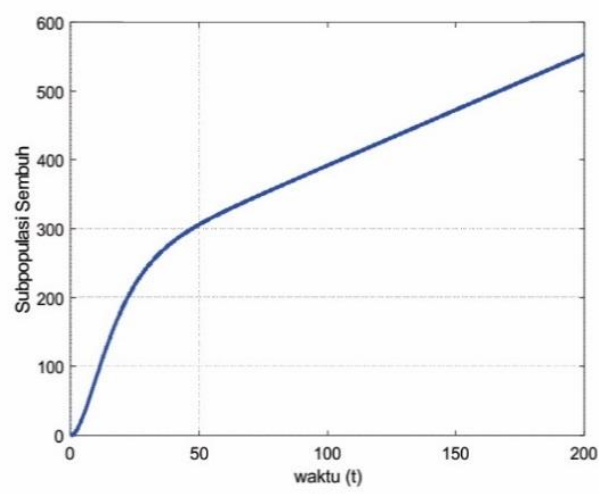

(g)

Figure 2. Numerical solutions for the COVID-19 model with quarantine and isolation

\section{Sensitivity analysis}

The sensitivity analysis is measured using a sensitivity index. The sensitivity index makes it possible to measure changes in the variable $R_{0}$ when one parameter value is increased or decreased while the other parameter values are maintained. A positive sensitivity index indicates that if the value of a parameter is decreased or increased by $10 \%$, then the value of $R_{0}$ will decrease or increase by $10 \%$. Conversely, a 
negative sensitivity index indicates that if the value of a parameter is decreased or increased, the value of $R_{0}$ will increase or decrease. The sensitivity analysis is obtained by the following command

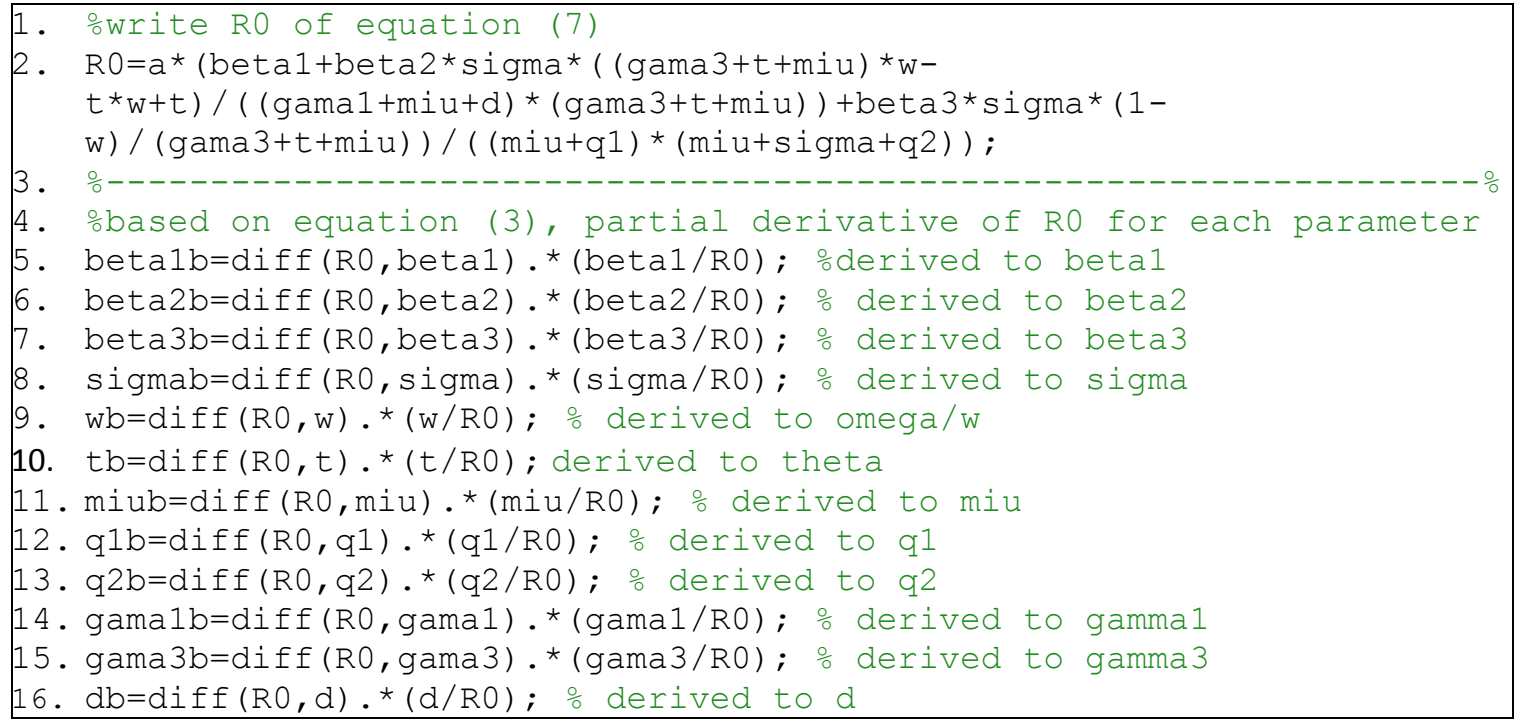

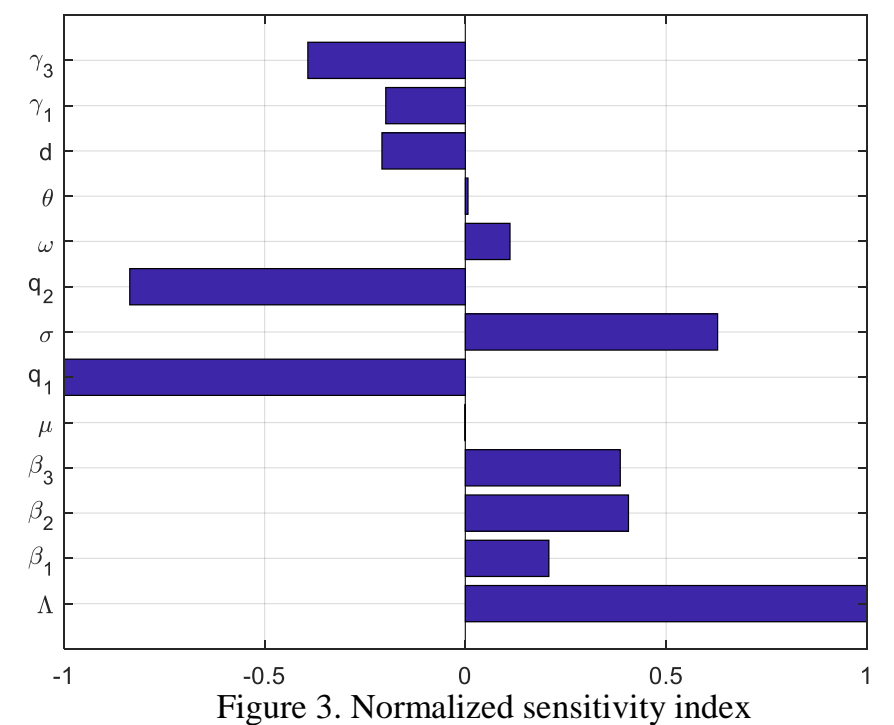

The normalized sensitivity index of $R_{0}$ is related to the parameters shown in Figure 3. Parameters that have a positive index, namely $\Lambda, \beta_{1}, \beta_{2}, \beta_{3}, \sigma, \omega$, and $\theta$ are a positive effect on $R_{0}$. It means an increase in value $\Lambda, \beta_{1}, \beta_{2}, \beta_{3}, \sigma, \omega, \theta$ can increase the $R_{0}$ value or cause an outbreak. Furthermore, the increase of parameters whose sensitivity index is negative is $q_{1}, q_{2}, \gamma_{3}, \gamma_{1}, d$ and $\mu$ a negative effect of minimizing the spread of disease. Furthermore, to specify the effect of changing parameter values on $R_{0}$, the value of each parameter is increased or decreased. Suppose that each parameter is increased or decreased by $10 \%$. Then the effect of changes in parameter values that are increased or decreased by $10 \%$ on $R_{0}$ is shown in Table 3 , sorted from most sensitive to less sensitive as follows.

Table 3. Effect of changes in parameter values

\begin{tabular}{cccc}
\hline \multirow{2}{*}{ No } & \multirow{2}{*}{ Parameter } & \multicolumn{2}{c}{$R_{0}=7.5$} \\
\cline { 3 - 4 } & & $\mathrm{p}+10 \%$ & $\mathrm{p}-10 \%$ \\
\hline 1 & $\Lambda$ & 8.2741 & 6.7697 \\
\hline 2 & $\mathrm{q}_{1}$ & 6.8383 & 8.3572 \\
\hline 3 & $\mathrm{q}_{2}$ & 6.9417 & 8.2079 \\
\hline 4 & $\sigma$ & 7.9868 & 7.0415 \\
\hline
\end{tabular}




\begin{tabular}{ccccc}
5 & & $\beta_{2}$ & 7.8274 & 7.2163 \\
\hline 6 & $\gamma_{3}$ & 7.2526 & 7.8483 \\
\hline 7 & $\beta_{3}$ & 7.8121 & 7.2317 \\
\hline 8 & $\beta_{1}$ & 7.6783 & 7.3654 \\
\hline 9 & $\mathrm{~d}$ & 7.3731 & 7.6867 \\
\hline 10 & $\gamma_{1}$ & 7.3797 & 7.6787 \\
\hline 11 & $\omega$ & 7.6055 & 7.4382 \\
\hline 12 & $\theta$ & 7.5268 & 7.5169 \\
\hline 13 & $\mu$ & 7.5212 & 7.5226 \\
\hline
\end{tabular}

After doing the analysis, the parameters are increased or decreased by $10 \%$. Then an example is given a simulation of the effect of increasing or decreasing parameters applied to all subpopulations, as shown in Figure 4 and Figure 5 below.

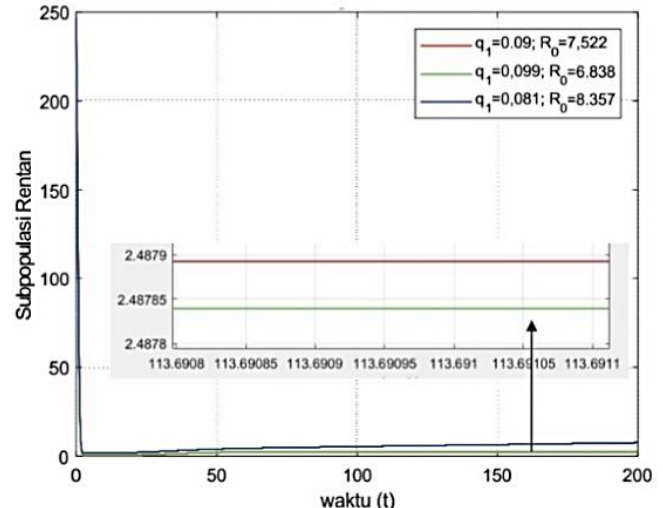

(a)

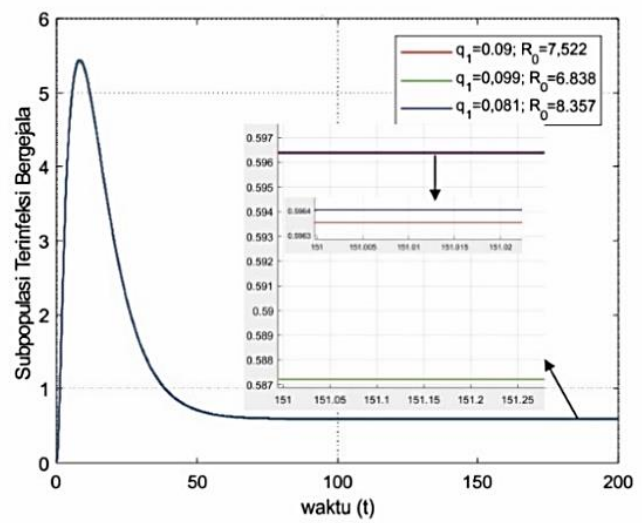

(c)

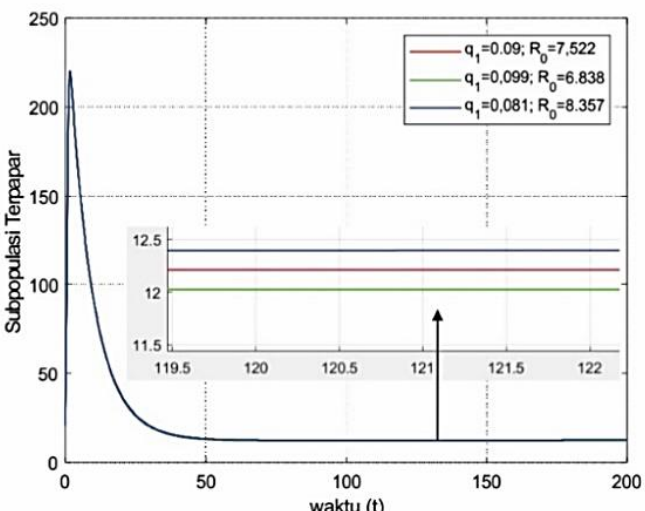

(b)

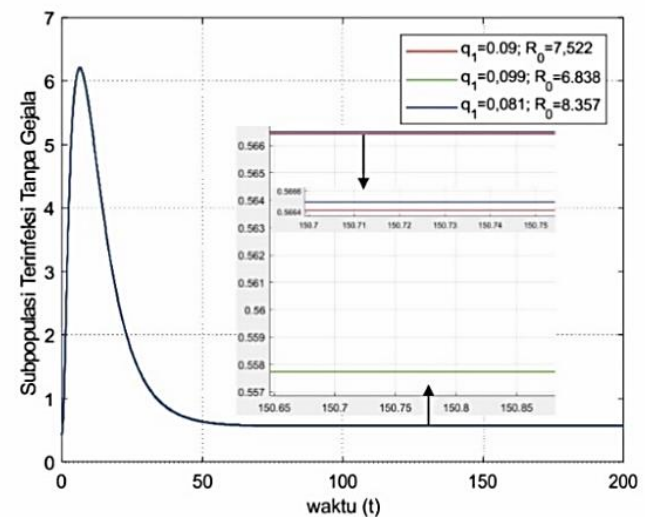

(d)

Figure 4. Simulation of the effect of changes in parameter values 


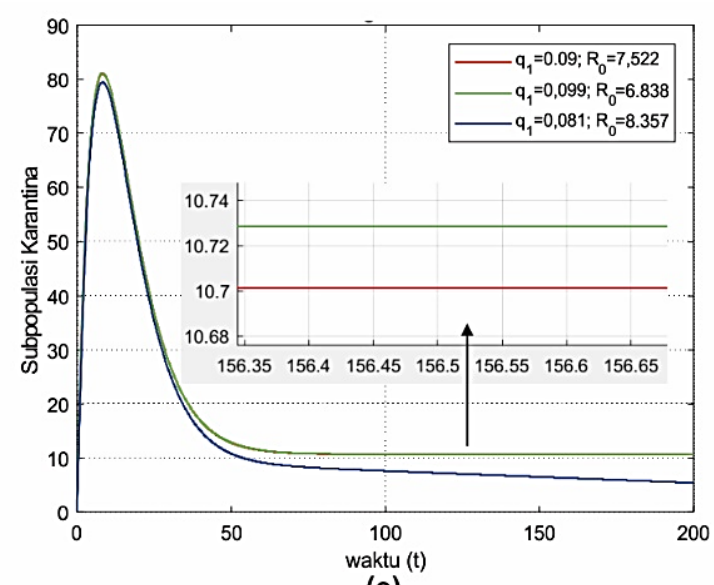

(e)

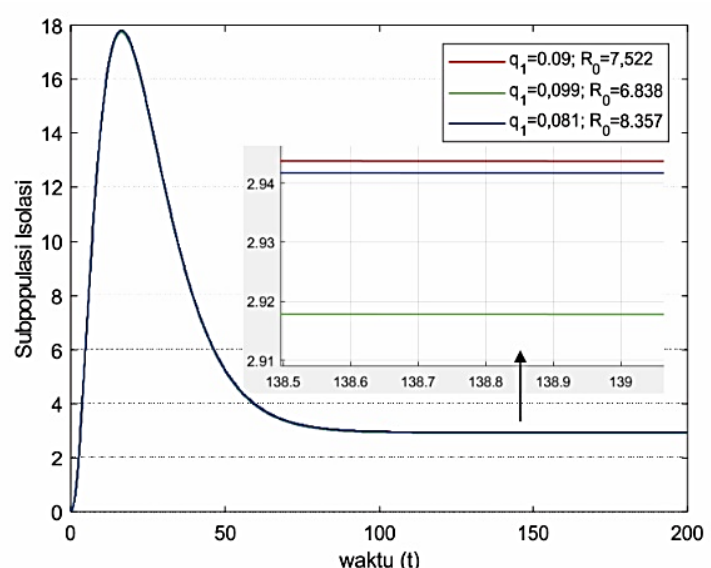

(f)

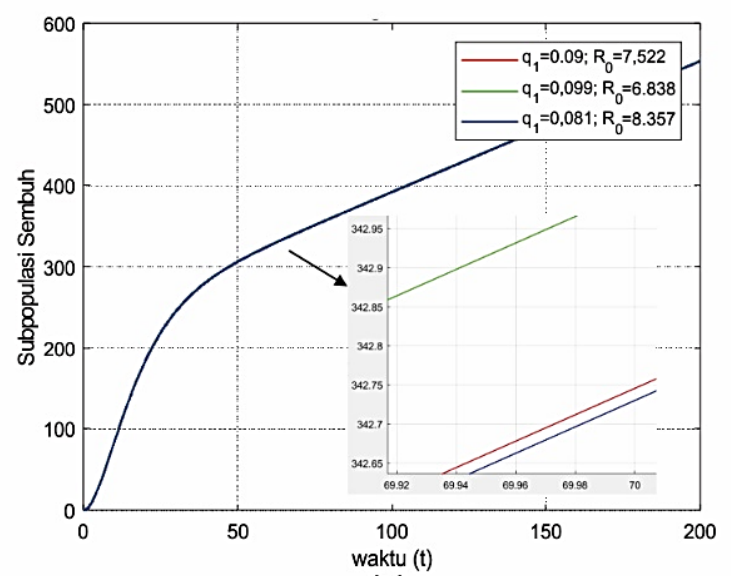

(g)

Figure 5. Next simulation of the effect of changes in parameter values

Figure 4 and Figure 5 show that the increase and decrease in parameters that affect the spread of COVID-19 will affect each subpopulation, especially in the exposed, symptomatic, and asymptomatic subpopulations. This also affects the quarantine and isolation subpopulations in response to an increase or decrease in infections. The reason is, these parameters have proven to be the most influential in increasing the outbreak and reducing outbreak COVID-19.

In this study, from Table 3, one parameter is taken to be used as an example of a graph of these parameters' influence. The parameter is taken $q_{1}$, and the parameter effect graph is shown in Figure 4 and Figure 5. Increasing and decreasing the $q_{1}$ parameter by $10 \%$ can change the value of $R_{0}$. Because $q_{1}$ has a negative effect, it means that if the parameter value of $q_{1}$ is increased by only $10 \%$, the value of $R_{0}$ will decrease, but if the value of the parameter $q_{1}$ is reduced by $10 \%$, the value of $R_{0}$ will increase.

Furthermore, the parameters obtained using the normalized sensitivity index in Figure 3 have positive and negative values. The parameters that have a positive effect are $\Lambda, \beta_{1}, \beta_{2}, \beta_{3}, \sigma, \omega, \theta$ and it means that if the parameters that have a positive effect are increased or decreased by only $10 \%$, the $R_{0}$ the value will increase or decrease. Then, the parameters that have a negative effect are $q_{1}, q_{2}, \gamma_{3}, \gamma_{1}, d, \mu$ and it means that if the parameters have a negative effect are increased or decreased by $10 \%$, the value of $R_{0}$ will decrease or increase. Therefore, to control the spread of COVID-19 decreases, we can increase negative parameters and decrease positive parameters in Figure 3. 


\section{CONCLUSIONS AND RECOMMENDATIONS}

The results of completing the COVID-19 model with quarantine and isolation are in equation (4), and with the initial values in Table 1 using the fourth-order Runge-Kutta method, it is found that the COVID-19 disease is endemic (Figure 2 and Figure 3 ) and is proven by the value $R_{0}=7.5$. After conducting a sensitivity analysis, several parameters that have the most influence in the spread of COVID19 are obtained, namely $\Lambda, q_{1}, q_{2}, \sigma, \beta_{2}, \gamma_{3}, \beta_{3}, \beta_{1}, d, \gamma_{1}, \omega, \theta, \mu$. From the sensitivity analysis, it can provide to selection of effective control measures in equation (4) to reduce the severity of the outbreak or eliminate the COVID-19 outbreak.

This study uses parameters from previous studies, and some are assumed so that if applied to this model it is not necessarily $100 \%$ valid, it is necessary to estimate parameters that are considered not knowing the exact value such as $\Lambda, \beta_{1}, \beta_{2}, \beta_{3}, \sigma, q_{1}, q_{2}, \gamma_{1}, \gamma_{2}, \gamma_{3}$. Then several algorithms can also be compared to complete parameter estimates, for example, the trust-region algorithm (subroutine fminsearch), genetic algorithms, PSO (Particle Swarm Optimization) algorithms, and others. Furthermore, it can also be developed to take control measures to solve the COVID-19 disease outbreak based on parameter sensitivity analysis.

\section{REFERENCES}

-. (2020). Report Coronavirus Cases. https://www.worldometers.info/coronavirus/

Aldila, D., Ndii, M. Z., \& Samiadji, B. M. (2020). Optimal Control on COVID-19 Eradication Program in Indonesia under the Effect of Community Awareness. Mathematical Biosciences and Engineering, 17(6), 6355-6389. doi: 10.3934/mbe.2020335

Belgaid, Y., Helal, M., \& Venturino, E. (2020). Analysis of a Model for Coronavirus Spread. Mathematics, 8(5), 1-30. https://doi.org/10.3390/math8050820

Brauer, F., \& Castillo-Chavez, C. (2012). Mathematical Models in Population Biology and Epidemiology. The American Mathematical Monthly (Second Edi., Vol. 110). New York: Springer-Verlag New York. DOI: 10.1007/978-1-4614-1686-9\_7

Chen, T. M., Rui, J., Wang, Q. P., Zhao, Z. Y., Cui, J. A., \& Yin, L. (2020). A Mathematical Model for Simulating the Phase-Based Transmissibility of a Novel Coronavirus. Infectious Diseases of Poverty, 9(1), 1-8. Infectious Diseases of Poverty. https://doi.org/10.1186/s40249-020-00640-3

Chitnis, N., Hyman, J. M., \& Cushing, J. M. (2008). Determining Important Parameters in the Spread of Malaria through the Sensitivity Analysis of a Mathematical Model. Bulletin of Mathematical Biology, 70(5), 1272. DOI: 10.1007/s11538-008-9299-0

Heffernan, J. M., Smith, R. J., \& Wahl, L. M. (2005). Perspectives on the Basic Reproductive Ratio. Journal of the Royal Society Interface, 2(4), 281-293. doi: 10.1098/rsif.2005.0042

Ingalls, B. (2012). Mathematical Modelling in Systems Biology: An Introduction. Waterloo: University of Waterloo.

Jia, J., Ding, J., Liu, S., Liao, G., Li, J., Duan, B., Wang, G., et al. (2020). Modeling the Control of COVID19: Impact of Policy Interventions and Meteorological Factors. Electronic Journal of Differential Equations, 2020(23), 1-24.

Lenhart, S., \& Workman, J. T. (2007). Optimal Control Applied to Biological Models. New York: Chapman and Hall/CRC.

Müller, J., \& Kuttler, C. (2015). Methods and Models in Mathematical Biology. Methods and Models in Mathematical Programming. London: Springer-Verlag Berlin Heidelberg. DOI: 10.1007/978-3$642-27251-6$ 
Murray, J. D. (2002). Mathematical Biology I: An Introduction (3rd ed., Vol. 17). New York: SpringerVerlag Berlin Heidelberg.

Sasmita, N. R., Ikhwan, M., Suyanto, S., \& Chongsuvivatwong, V. (2020). Optimal Control on a Mathematical Model to Pattern the Progression of Coronavirus Disease 2019 (COVID-19) in Indonesia. Global Health Research and Policy, 5.

Soewono, E. (2020). On the Analysis of Covid-19 Transmission in Wuhan, Diamond Princess, and Jakartacluster. Communication in Biomathematical Sciences, 3(1), 9-18.

Sumartiningtyas, H. K. N. (2020, March 2). Update Virus Corona 2 Maret: 89.212 Orang di 68 Negara Terinfeksi. KOMPAS. Retrieved from https://sains.kompas.com/read/2020/03/02/170200123/update-virus-corona-2-maret-89212-orangdi-68-negara-terinfeksi?page=all

Tang, B., Wang, X., Li, Q., Bragazzi, N. L., Tang, S., Xiao, Y., \& Wu, J. (2020). Estimation of the Transmission Risk of the 2019-nCoV and Its Implication for Public Health Interventions. Journal of Clinical Medicine, 9(2), 462. doi: 10.3390/jcm9020462

WHO. (2020). Pertimbangan-pertimbangan untuk karantina individu dalam konteks penanggulangan penyakit coronavirus (COVID-19). Retrieved from https://www.who.int/docs/defaultsource/searo/indonesia/covid19/who-2019-covid19-ihr-quarantine-2020indonesian.pdf?sfvrsn=31d7cbd8_2

Yousefpour, A., Jahanshahi, H., \& Bekiros, S. (2020). Optimal Policies for Control of the Novel Coronavirus Disease (COVID-19) Outbreak. Chaos, Solitons and Fractals, 136. https://doi.org/10.1016/j.chaos.2020.109883

Zeb, A., Alzahrani, E., Erturk, V. S., \& Zaman, G. (2020). Mathematical Model for Coronavirus Disease 2019 (COVID-19) Containing Isolation Class. BioMed Research International, 2020. https://doi.org/10.1155/2020/3452402 